\title{
Modeling the dispersion of Ambrosia artemisiifolia L. pollen with the model system COSMO-ART
}

\author{
Katrin Zink • Heike Vogel • Bernhard Vogel • \\ Donát Magyar • Christoph Kottmeier
}

Received: 5 May 2011 /Revised: 16 June 2011 / Accepted: 17 June 2011 / Published online: 9 July 2011

(C) The Author(s) 2011. This article is published with open access at Springerlink.com

\begin{abstract}
Common ragweed (Ambrosia artemisiifolia L.) is a highly allergenic plant that is spreading throughout Europe. Ragweed pollen can be transported over large distances by the wind. Even low pollen concentrations of less than 10 pollen $\mathrm{m}^{-3}$ can lead to health problems in sensitive persons. Therefore, forecasting the airborne concentrations of ragweed pollen is becoming more and more important for public health. The question remains whether distant pollen sources need to be considered in reliable forecasts. We used the extended numerical weather prediction system COSMO-ART to simulate the release and transport of ragweed pollen in central Europe. A pollen episode (September 12-16, 2006) in northeastern Germany was modeled in order to find out where the pollen originated. For this purpose, several different source regions were taken into account and their individual impact on the daily mean pollen concentration and the performance of the forecast were studied with the means of a $2 \times 2$ contingency table and skill scores. It was found that the majority of the pollen originated in local areas, but up to $20 \%$ of the total pollen load came from distant sources in Hungary. It is concluded that long-distance transport should not be neglected when predicting pollen
\end{abstract}

K. Zink $\cdot$ H. Vogel $(\bowtie) \cdot B$. Vogel $\cdot$ C. Kottmeier Institute for Meteorology and Climate Research, Karlsruhe Institute of Technology,

Karlsruhe, Germany

e-mail: heike.vogel@kit.edu

D. Magyar

Department of Aerobiological Monitoring,

National Institute of Environmental Health,

Budapest, Hungary concentrations.

Keywords COSMO-ART · Pollen dispersal $\cdot$ Numerical modeling $\cdot$ Pollen forecast $\cdot$ Ragweed

\section{Introduction}

Common ragweed (Ambrosia artemisiifolia L.; in the following, the popular name 'ragweed' will be used) was introduced into Europe during the second half of the nineteenth century. It remained insignificant in most of Europe for more than a century. During the last two decades, an accelerated spread of the plant has been observed. Nowadays, small populations of the plant can be found in almost every European country up to the southern part of Sweden (e.g., Dahl et al. 1999; Jäger 2000; Rybníček et al. 2000; Taramarcaz et al. 2005; Albertenst and Nawrath 2006; Köhler et al. 2006; Trigo and GarcíaSánchez 2006). Larger populations of the species have been reported in several Central European countries in the Carpathian basin, namely Hungary, Croatia, Serbia, and Slovakia (e.g., Járai-Komlódi 2000; Makra et al. 2004). Furthermore, significant populations can be found in northern Italy and the Rhône-Alpes region in France (e.g., Mandrioli et al. 1998; Laaidi and Laaidi 1999; Zanon et al. 2002; Laaidi et al. 2003).

It has been shown that concentrations down to $5-10$ ragweed pollen $\mathrm{m}^{-3}$ can lead to health problems for sensitive persons (Taramarcaz et al. 2005). The consequential costs for the treatment of patients allergic to ragweed are estimated to lie between $€ 19$ and 50 million for Germany (Reinhardt et al. 2003). Ragweed flowers late in the year compared to most other allergenic plants in 
central Europe, hereby prolonging the season in which allergies occur.

Ragweed is an annual plant that can reach heights between 0.1 and $2 \mathrm{~m}$. The allergenic pollen is produced in the male flowers that are situated in the upper part of the plant, above the foliage. The main flowering season begins in August and ends in October, but minor amounts of airborne pollen can also be found in June and November. The pollen production (the amount of pollen one plant can produce during 1 year) amounts to about $10^{9}$ pollen grains for a full-grown plant (Fumanal et al. 2007). According to Taramarcaz et al. (2005), the pollen diameter lies between 18 and $22 \mu \mathrm{m}$. The density of ragweed pollen grains varies greatly with humidity since they are composed of air-filled voids. In high relative humidity, the pollen grains swell, hereby filling the voids partially. Saturated grains have a density of about $1,200 \mathrm{~kg} \mathrm{~m}^{-3}$, while dry pollen grains weigh about $830 \mathrm{~kg} \mathrm{~m}^{-3}$ (Mandrioli et al. 2003). Before being emitted into the atmosphere, the pollen is saturated. As soon as it is airborne, evaporation starts and the pollen dries up. According to Mandrioli et al. (2003), the evaporation rate of a pollen grain reaches values of the magnitude of the evaporation rate of a water droplet of the same size. The emission process starts when the anthers dry and break up. After Bianchi et al. (1959), the dehiscence of the anthers requires a low relative humidity and high temperatures, but exact values are not given. Emission mainly takes place during the morning hours: it starts shortly after sunrise and continues until early afternoon (e.g., Bianchi et al. 1959; Dingle et al. 1959; Laaidi and Laaidi 1999).

The most effective way of reducing allergic symptoms is to avoid the allergen completely. It is therefore of great interest to know of airborne pollen concentrations a few days in advance. Nowadays, pollen forecasts are mainly based on pollen monitoring and weather forecasts (Group Bio and Environmental Meteorology, MeteoSwiss, personal communication). A decisive factor for the quality of the forecast is whether distant sources need to be considered or not. Thus, the questions are: does long-distance transport of ragweed pollen take place and to what extent does this influence local pollen concentrations?

Usually, this question is addressed by examining temporal patterns of pollen concentrations. Indicators for long-distance transport of pollen can be: (1) the time of day when maximal pollen concentrations occur: ragweed flowers in the morning, local sources lead to maximum concentrations during morning and midday hours, remote sources lead to maximum concentrations during afternoon or even night hours (e.g., Laaidi and Laaidi 1999); (2) the temporal variability of daily pollen counts: local sources lead to a continuing pollen season while short individual pollen episodes are a sign of distant sources (e.g., Cecchi et al. 2006); (3) correlations between the temporal patterns of pollen concentrations in different locations (e.g., Clot et al. 2002); or (4) the recurrence of pollen outside the local pollen season (e.g., Makra and Pálfi 2007). Possible source regions of the pollen can be found by examining the synoptic situation and through back trajectory analyses (e.g., Makra et al. 2010). Numerous studies have been undertaken to quantify the influence of remote sources on local pollen concentrations (e.g., Belmonte et al. 2000; Cecchi et al. 2007; Kasprzyk 2008; Köhler et al. 2006; Piotrowska and Weryszko-Chmielewska 2006; Puc 2006; Saar et al. 2000; Skjøth et al. 2010; Smith et al. 2008; Stach et al. 2007). According to some of these studies, the pollen concentrations in various European regions depend mainly on long-distance transport. Not surprisingly, the majority of pollen is assumed to originate in southern Hungary, northern Italy and the Rhône-Alpes region in France, those being the regions with the highest density of ragweed plants in Europe.

Another approach to examining long-distance transport of pollen is by incorporating pollen grains into numerical weather forecast systems and explicitly calculating their dispersal. In order to do so, physical equations and parameterizations need to be found for all the processes the pollen is subjected to during its passage through the atmosphere. Furthermore, detailed distribution maps of the plant are necessary. Despite the uncertainties concerning the formulas and the plant distribution, this modeling approach shows several advantages: the punctual measurements of pollen concentrations cannot show the temporal and spatial evolution of pollen clouds. Back-trajectory analyses can show possible source regions of pollen, but it is not guaranteed that pollen actually is in the transported air masses. Another advantage of modeling the pollen dispersal is its potential for forecasting the pollen load a few days in advance. Several atmospheric model systems have already been expanded with pollen formulations. A brief overview follows.

Helbig et al. (2004) proposed a parameterization of the emission of pollen depending on meteorological variables as wind stress, temperature and humidity. This parameterization was incorporated into the model system KAMM/ DRAIS/MADEsoot (Riemer et al. 2003). It was applied to an isolated field in the Rhine Valley. Helbig et al. (2004) have shown that, especially in inhomogeneous terrain where secondary circulation systems are generating vertical velocities substantially greater than zero, the pollen grain can travel greater distances.

The same formulations were included in the comprehensive model system COSMO-ART (Vogel et al. 2008). They simulated a birch (Betula) pollen episode of 2006 and showed the feasibility of this method for a daily pollen forecast.

The distribution of oak (Quercus) pollen was modeled with a combination of the atmospheric model MM5 and the 
trajectory model HYSPLIT 4 (Pasken and Pietrowicz 2005). Emission of pollen was not coupled with atmospheric conditions. The emission strength per unit area did not change over time and latitude. The pollen trajectories accounted for sedimentation and wet deposition.

Oak pollen were also modeled by means of the atmospheric model METRAS (Schueler and Schlünzen 2006). Pollen concentrations depended on advection, turbulent diffusion, pollen emission, sedimentation, and pollen viability. Meteorological factors influencing pollen emission were taken into account.

The Finnish model SILAM was used to model the dispersal of birch pollen (Sofiev et al. 2006). The transport of the pollen in the atmosphere was governed by advection, dry and wet deposition. Two approaches were carried out. Firstly, the model was fed with measured concentrations and possible source regions were calculated. And secondly, pollen was emitted in the model and its transport was calculated.

As a conclusion, one can say that atmospheric models are capable of simulating pollen dispersion. The main problem is the input data (plant distribution and characteristics of pollen emission).

In September 2006, uncommonly high numbers of ragweed pollen were found in pollen traps throughout Eastern Germany. The registered pollen concentrations reached 41 pollen $\mathrm{m}^{-3}$, hereby easily exceeding the allergenic threshold of 10 pollen $\mathrm{m}^{-3}$. In order to address the question whether this pollen came from sources inside Germany or was brought to the region by long-distance transport, ragweed pollen was introduced into the numerical weather forecast model system COSMO-ART. The emission flux was parameterized according to Helbig et al. (2004) and Vogel et al. (2008). The distribution of plants took into account sources in Germany, Austria, Hungary and the Czech Republic. Several runs were carried out, each time taking into account a different set of source regions. The resulting pollen distributions were compared to measurements by means of a $2 \times 2$ contingency table. Different skill scores were calculated in order to find out the importance of the individual source region for the total pollen load in eastern Germany.

\section{Materials and methods}

\section{The model system COSMO-ART}

The COSMO-model (Consortium for Small-scale Modeling) is the operational weather forecast model (Steppeler et al. 2002) of the German Weather Service (DWD). The extension of COSMO to the online coupled model system COSMO-ART (Aerosols and Reactive Trace Gases) was developed to simulate the interaction between aerosols and the atmosphere on the regional scale. It was applied to study the impact of mineral dust (Stanelle et al. 2010), sea salt (Lundgren et al. 2011) and secondary aerosols (Vogel et al. 2009) on radiation and on warm clouds (Bangert et al. 2011). A more detailed description of COSMO-ART can be found in Vogel et al. (2009).

In order to incorporate pollen into a numerical weather forecast system, several processes need to be considered. The life cycle of airborne pollen starts with the emission of pollen grains from the flower. After that, they are transported through the atmosphere and finally deposited on surfaces. The parameterizations used in our approach follow the ones of Helbig et al. (2004) and Vogel et al. (2008). All relevant formulas can be found there. Processes that are being taken into account are the emission flux of pollen into the air, their advection by the mean wind, their diffusion through atmospheric turbulence, dry and wet deposition, as well as wash-out processes. Biological as well as meteorological influences on the emission flux are being considered, e.g., time of the day, progress into the pollen season, temperature, relative humidity, or wind speed.

\section{Plant distribution}

In order to calculate the emission flux of pollen, the location and abundance of ragweed plants has to be known. Unfortunately, the available data are neither up-to-date nor precise. Since ragweed is an annual plant and usually dispersed and also eradicated by humans, plant distribution data are not valuable for a long period of time. The analyzed pollen episode with south-easterly winds required the consideration of source regions in central and southeastern Europe. Distribution maps and digital data of Germany, Austria, Hungary, and the Czech Republic were considered. The quality of distribution data varies strongly. For Hungary, a map is available showing the percentage of land covered by ragweed plants, thus giving classified information about the number of plants shedding pollen (Páldy et al. 2006; Novák et al. 2009). A map with stands of ragweed plants in the Czech Republic can be found in Rybníček et al. (2000). Unfortunately, the map does not show the abundance of plants per stand. The same is true for a distribution map covering Germany (http://www. ambrosiainfo.de, Albertenst and Nawrath 2006). Regions where big ragweed stands of more than 100 plants can be found are indicated. But the actual abundance of each plant stand or the number of ragweed stands per region is not shown. Digital data for Austria and Germany gives the location and first encounter of stands (Kleinbauer, personal communication).

In order to use the distribution data in a model simulation, the maps had to be digitalized and the data 
homogenized. Since the Hungarian map shows the most detailed information, it was used as the base line for the homogenization. An exact number giving the fraction of land occupied by ragweed was assigned to each Hungarian grid point in the model domain. This number represents the abundance of ragweed plants in the corresponding pixel of the Hungarian distribution map. In order to do this, the map was edited and read via the program Matlab. That way, the color of each pixel of the map could be determined with each color representing a certain abundance of ragweed plants. In a second step, the approximate longitude and latitude of each pixel was identified through an overlay with a geographical map of the region.

The remaining distribution data-maps and lists-were not as detailed. Only longitudinal and latitudinal information of plant stands was available. To each plant location in the distribution data, the closest grid point in the model domain was assigned. Since no information about the abundance is at hand, a reasonable value for the plant coverage had to be found. Knowing that in Hungary the density of ragweed plants is much higher than in the Czech Republic, Austria, and Germany, the lowest category of plant abundance in the Hungarian map was used for all of the plant stands in these three countries. The resulting distribution map for the model domain can be seen in Fig. 1.

\section{Measurements of pollen concentrations}

In Germany, pollen concentrations are measured by the PID (Stiftung Deutscher Polleninformationsdienst 2009) in cooperation with the DWD using Burkhard pollen traps. For comparison with our simulated concentrations, we used the daily pollen concentrations of 43 stations in Germany during the summer of 2006. The location of the monitoring stations can be seen in Fig. 2.

\section{Simulations}

An episode in 2006 (September 12-17) was chosen because it showed uncommonly high ragweed pollen concentrations in several monitoring stations in northeastern Germany. They were accompanied by southeasterly winds. Back-trajectory analyses (Gabrio et al. 2008) suggest that a certain ratio of this pollen might have originated in Hungary. In order to find out whether this assumption might be correct, several numerical simulations of the episode were carried out. The only difference between the simulations is the distribution of ragweed stands that were considered. Table 1 gives an outline of the parameters and values used in the simulations.

A total of 15 simulations were carried out using all possible combinations of source regions (see Table 2). The goal of that approach was to describe the influence of the different source regions on the pollen concentration in north-eastern Germany. Two questions need to be answered:
Fig. 1 Ragweed (Ambrosia artemisiifolia) distribution map for Germany, Austria, the Czech Republic, and Hungary, showing the percentage of the grid box covered with ragweed plants as used in the simulations

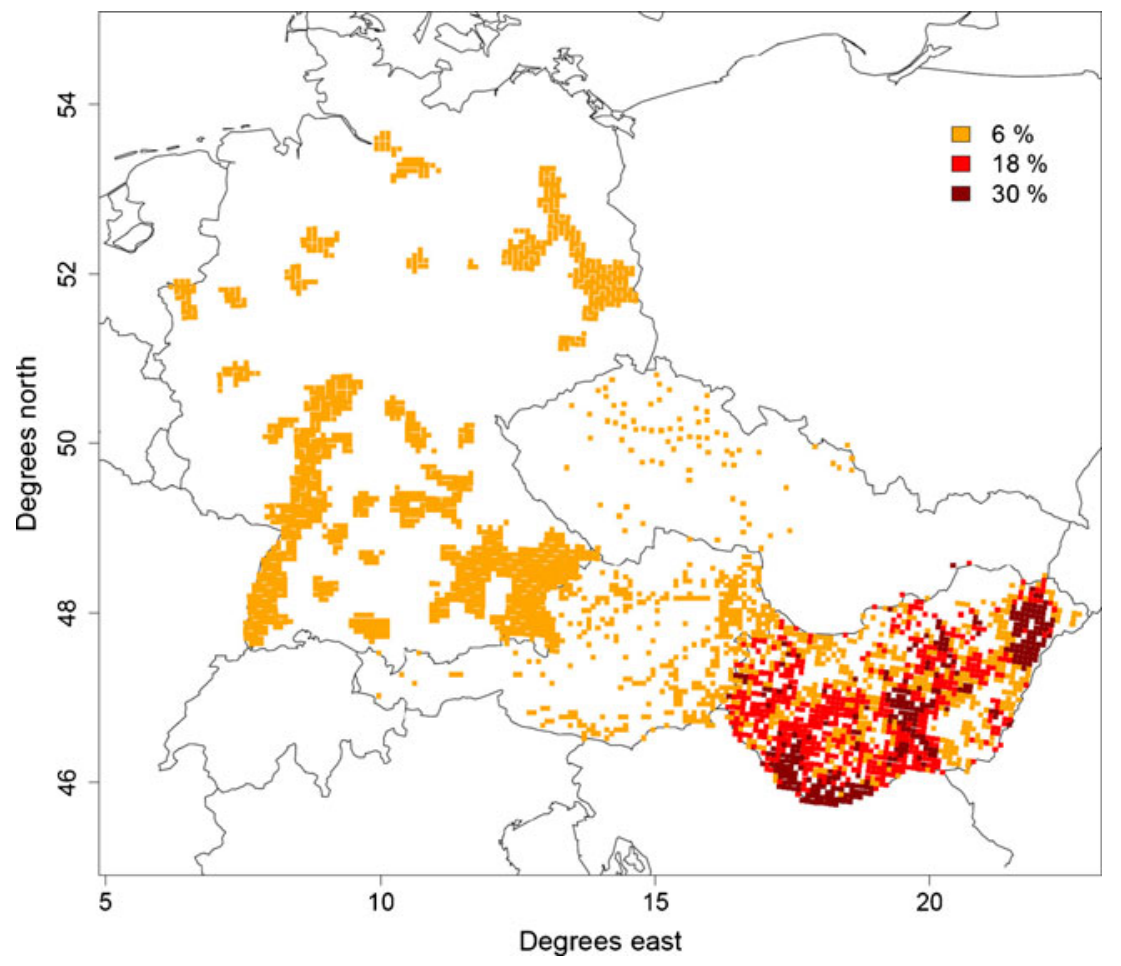

1. How big is the influence of long-range transport on local pollen concentrations? 


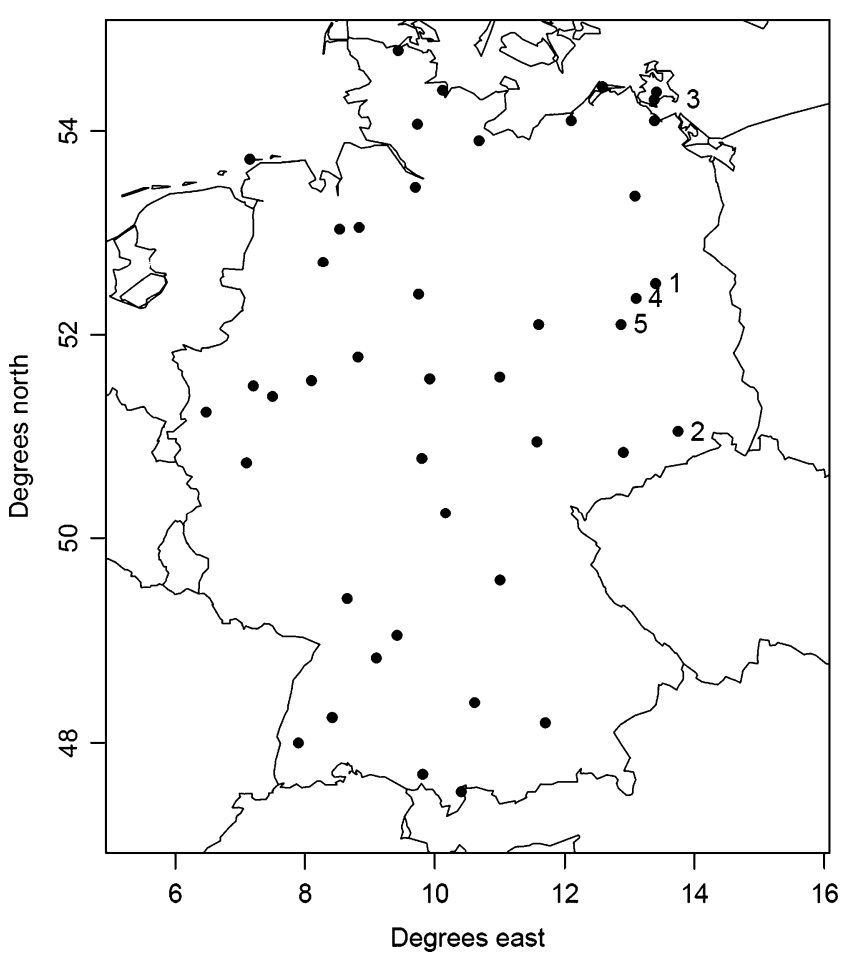

Fig. 2 Pollen monitoring sites in Germany. The stations that are mentioned in the text are 1 Berlin, 2 Dresden, 3 Garz, 4 Potsdam, and 5 Treuenbrietzen

2. Can the performance of the pollen forecast be improved by considering distant pollen sources instead of only considering local plant stands?

The first question is addressed by running the model four times, each time using just one of the four available source regions (Germany, Hungary, Austria, and the Czech Republic). The total pollen load for each grid point can then be calculated as the sum of the pollen load of the four simulations, that way finding the percentage that each source region adds to the total pollen load.

The second question is addressed by running the model 15 times, each time using a different combination of the source regions. A $2 \times 2$ contingency table is then applied to evaluate and rank the 15 simulations. By this means, the source regions that are essential for a good pollen forecast in the specified region shall be identified.

\section{Contingency table and skill scores}

A contingency table (Fig. 3) was used to calculate skill scores that can describe the performance of the model. This validation method is used in weather forecasts when the occurrence of an incident is more important than its strength. In our case, the question "Is a certain pollen threshold reached?" can be answered. If this question refers to the agreement of measurements and simulation, four different answers are possible:

a - a pollen event is simulated and measured (hit)

b - a pollen event is simulated but not measured (false alarm)

c - a pollen event is not simulated but measured (miss)

$\mathrm{d}$ - a pollen event is neither simulated nor measured (correct negation)

The frequency of each answer is recorded in the contingency table and skill scores are computed using the letters $\mathrm{a}, \mathrm{b}, \mathrm{c}$, and $\mathrm{d}$. We decided to use the following skill scores: Proportion Correct (PC), Threat Score (TS), Bias (B), Hit Rate $(\mathrm{H})$, False Alarm Rate $(\mathrm{F})$, and the Heidke Skill Score (HSS). The formulations and descriptions of these skill scores can be found in Wilks (2006).

\section{Results and discussion}

Simulations with all available source regions

In order to compare the spatial variation of pollen concentrations in the model to the measured pollen concentrations, a simulation using all four available source regions (Germany, Austria, the Czech Republic, Hungary) was carried out. On September 13 and 14, the wind velocity over Germany is rather low. Over Hungary and the Czech Republic, stronger winds from south-easterly directions prevail (Fig. 4). Pollen emission in the model can only occur when certain threshold values for temperature and relative humidity are reached. In the relevant model regions, the meteorological conditions favor pollen emission, since the threshold values for both temperature and relative humidity are exceeded. Figure 5 shows the simulated pollen concentration as background shading, while the measurements are plotted with dots. One can easily see that a pollen cloud originating in Hungary is initially spreading out towards the north-eastern part of Germany. Many stations in north-eastern Germany measure pollen concentrations in the magnitude of 50 pollen grains $\mathrm{m}^{-3}$. All these stations are in the vicinity of the pollen cloud from Hungary, while the stations further south and west are not touched by the pollen cloud. Accordingly, the measuring stations there do not record pollen in the air. Single stations in southern and western Germany register low ragweed pollen concentrations that are most probably caused by local plants. On September 15 and 16, the wind is turning to easterly directions (Fig. 4). Hence, the pollen cloud from Hungary does not any longer reach the northeastern part of Germany, but instead influences regions in central and southern Germany. Especially on September 16, but to a lower extent also on September 15, some 
Table 1 Parameters and values used in the simulations

\begin{tabular}{|c|c|c|}
\hline Parameter & Value & Reference \\
\hline Simulated time period & $\begin{array}{l}\text { 12/09/2009, } 00 \text { UTC - 17/09/2009, } \\
\text { 00 UTC }\end{array}$ & \\
\hline Simulated domain & $\begin{array}{l}\text { Central Europe and neighboring } \\
\text { regions, } \sim 2,640 \times 1,735 \mathrm{~km}^{2}\end{array}$ & \\
\hline \multirow[t]{3}{*}{ Number of grid points } & $\mathrm{x}: 360$ & \\
\hline & y: 250 & \\
\hline & $\mathrm{z}: 40$ & \\
\hline Horizontal resolution & $0.0625^{\circ}(\sim 7 \mathrm{~km})$ & \\
\hline Time step & $40 \mathrm{~s}$ & \\
\hline Density of a dry ragweed pollen grain & $830 \mathrm{~kg} \mathrm{~m}^{-3}$ & Mandrioli et al. 2003 \\
\hline Diameter of a dry ragweed pollen grain & $20 \mu \mathrm{m}$ & Taramarcaz et al. 2005 \\
\hline $\begin{array}{l}\text { Diurnal time period where ragweed } \\
\text { flowering is allowed in the model }\end{array}$ & 6 to 10 UTC & Bianchi et al. 1959 \\
\hline \multirow{2}{*}{$\begin{array}{l}\text { Length of the ragweed pollen season } \\
\text { (S) in the model }\end{array}$} & \multirow[t]{2}{*}{90 days } & Járai-Komlódi 2000 \\
\hline & & Makra et al. 2004 \\
\hline $\begin{array}{l}\text { Leaf Area Index for ragweed (LAI) } \\
\text { in the model }\end{array}$ & 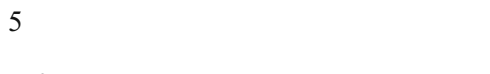 & Abul-Fatih et al. 1979 \\
\hline $\begin{array}{l}\text { Ragweed pollen production }\left(\mathrm{Q}_{\mathrm{P} 0}\right) \text { in } \\
\text { the model }\end{array}$ & $10^{9}$ pollen grains per plant and per year & Fumanal et al. 2007 \\
\hline Canopy height of ragweed in the model & $2 \mathrm{~m}$ & \\
\hline $\begin{array}{l}\text { Correction factor for small plants in } \\
\text { the model }\end{array}$ & 0.015 & \\
\hline $\begin{array}{l}\text { Temperature threshold for ragweed } \\
\text { pollen emission in the model }\left(\mathrm{T}_{\mathrm{te}}\right)\end{array}$ & $293 \mathrm{~K}$ & Bianchi et al. 1959 \\
\hline $\begin{array}{l}\text { Relative humidity threshold for } \\
\text { ragweed pollen emission in the } \\
\text { model }\left(\mathrm{U}_{\text {te }}\right)\end{array}$ & $60 \%$ & Bianchi et al. 1959 \\
\hline $\begin{array}{l}\text { Wind speed threshold for ragweed } \\
\text { pollen emission in the model }\left(\mathrm{v}_{\mathrm{te}}\right)\end{array}$ & $2.9 \mathrm{~m} / \mathrm{s}$ & Helbig et al. 2004 \\
\hline $\begin{array}{l}\text { Weighting factors for meteorological } \\
\text { parameters in the model }\left(\mathrm{c}_{1}, \mathrm{c}_{2}, \mathrm{c}_{3}\right)\end{array}$ & 1 & Helbig et al. 2004 \\
\hline
\end{tabular}

measuring sites in central Germany register a moderate ragweed pollen concentration. Coherently, this can be explained with long-range transport from Hungarian source

Table 2 Combinations of source regions that were considered in the 15 different simulation runs

$D$ Germany, $H$ Hungary, $A$ Austria, $C Z$ Czech Republic regions. However, many measuring sites in that region do not register any pollen, even though they are lying in the vicinity of the simulated pollen cloud. The pollen concentrations in north-eastern Germany that are still very high are probably caused by local plants. The wind coming mainly from eastern directions can also hint at plant stands east of

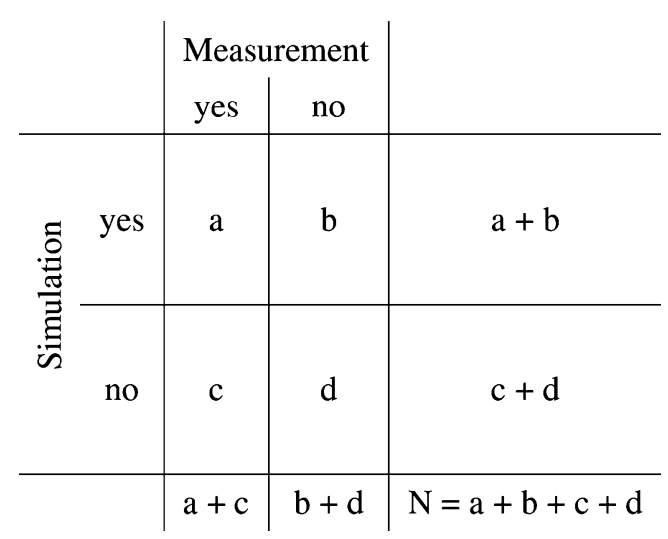

Fig. $32 \times 2$ contingency table. Hits (a), misses (b), false alarms (c), and correct negatives $(\mathbf{d})$ are summed in order to compute skill scores 

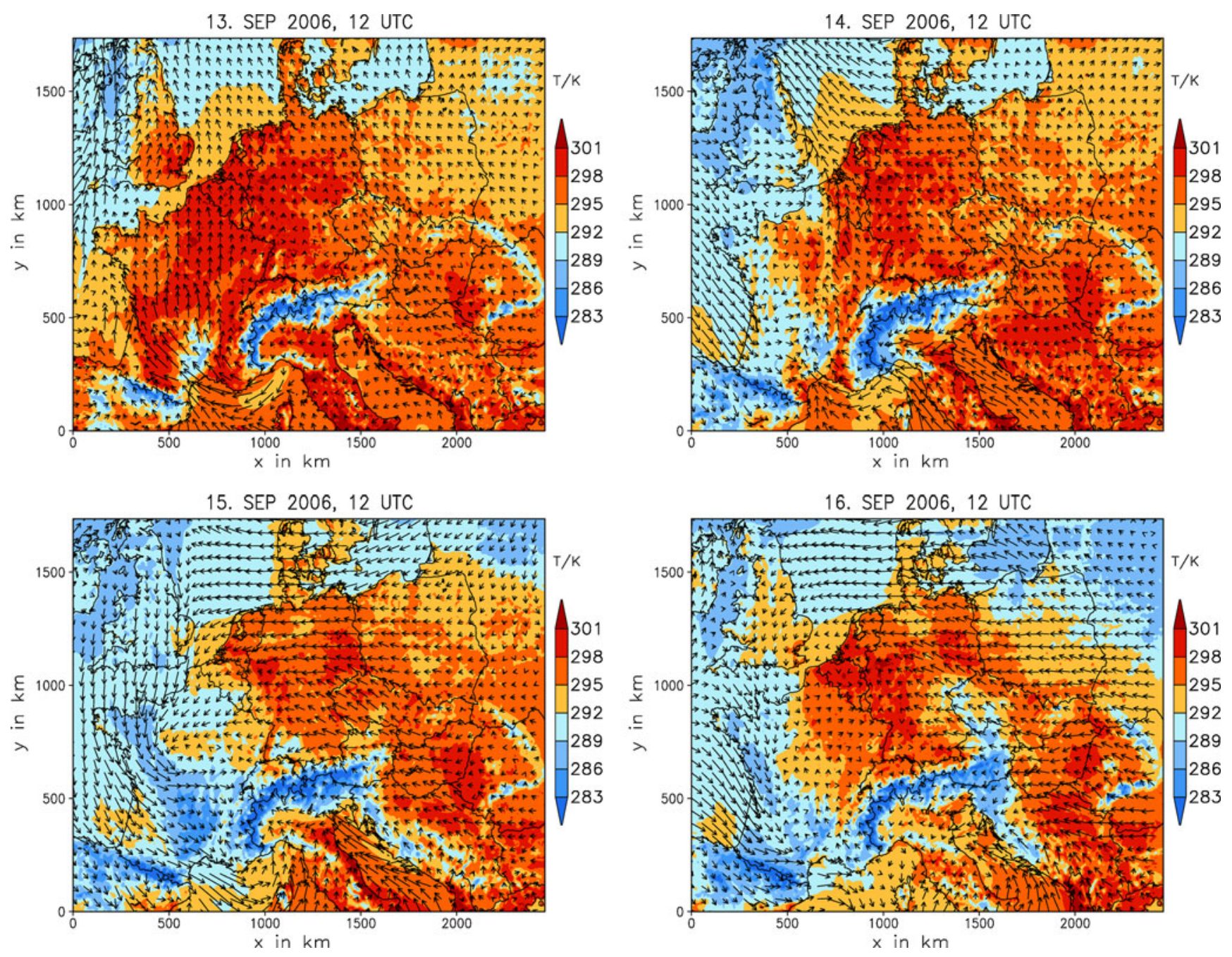

Fig. 4 Simulated temperature and wind vectors on the lowest model level from September 13 to 16, 2006

Germany that may influence the pollen concentrations in north-eastern Germany.

Overall, the spatial distribution of the measured pollen concentration can be simulated quite well. But a quantitative comparison between the absolute values of simulated and measured pollen concentrations shows that the results differ greatly in some parts.

Simulations with different combinations of source regions

\section{Geographical origin of the pollen}

On September 15, 2006, several measuring sites in Germany registered more than 10 pollen $\mathrm{m}^{-3}$. Table 3 shows the 'geographical composition' of the pollen concentration for some of the measuring sites as computed by the model. The strong influence of German sources can be depicted easily: in three of the five sites the pollen originating in Germany amounts to more than $80 \%$ of the total pollen load. Thus, the vast majority of pollen can be assigned to local sources.
Looking closely at the results, it can be seen that the two sites 'Dresden' and 'Garz' differ greatly from the other three sites. 'Garz' is situated north of the simulated pollen cloud, and thus the computed proportion of pollen origins is based on very low pollen concentrations. Therefore, the site is not considered here. 'Dresden' is a city close to the Czech border, hence most of the German pollen sources lie downwind of the site during south-easterly winds. In that case, the German sources are negligible and the Czech sources take over the role of local sources for regions in Germany that are close to the Czech border. As is the case for Germany, up to now ragweed plants are scarce in the Czech Republic. Thus, sources are punctual and cannot account for high pollen counts. This explains the big influence of Hungarian sources for the site 'Dresden' where more than $50 \%$ of the pollen load originates in Hungary. But the influence of the Hungarian sources can also be seen in the remaining three sites 'Berlin', 'Potsdam', and 'Treuenbrietzen'. Despite their distance, the Hungarian sources account for up to $17.5 \%$ of the total pollen load 

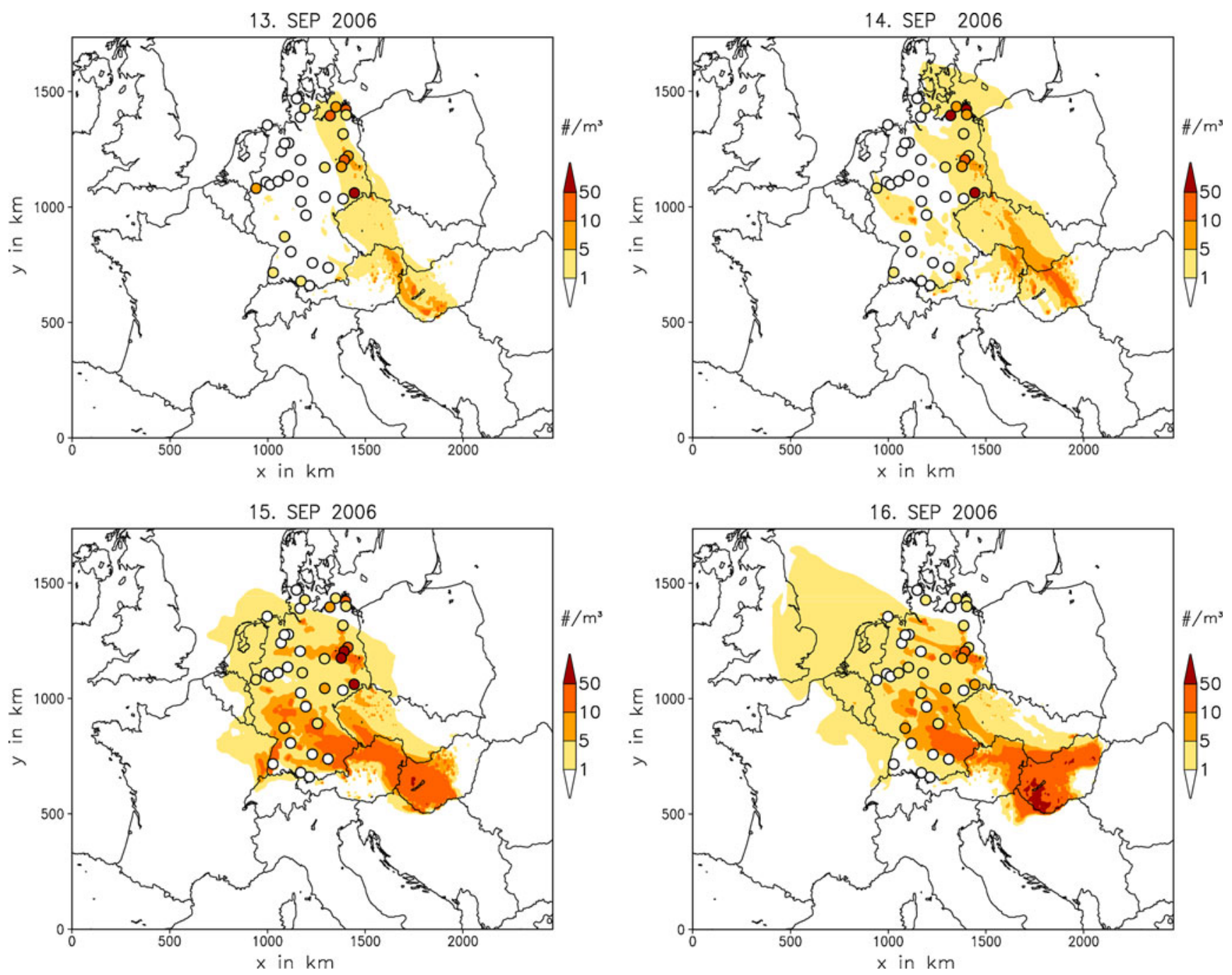

Fig. 5 Simulated and measured pollen concentrations from September 13 to 16, 2006. Dots represent measurements, while the shaded area depicts the simulated concentration. The concentrations are given in

daily mean values of pollen $\mathrm{m}^{-3}$ of air. The color scheme is the same for measurements and simulation. All available source regions (Germany, Austria, the Czech Republic, and Hungary) were used in the simulation

in these three German sites. This shows that the pollen release in Hungary should not be neglected when producing reliable pollen forecasts.

Noticeably, the impact of Austrian sources is very small. This may be a result of the general weather situation during the studied episode. Since the wind is coming from south-easterly directions, the Austrian

pollen is not transported towards north-eastern Germany. The small impact of Austrian sources can also be explained by about a magnitude smaller ragweed pollen concentration here (Jäger 2000) compared to that in Hungary (Makra et al. 2005).

A more thorough investigation of the influence of the individual source regions is constrained by the greatly

Table 3 Modeled proportion of the influence of individual source regions on the total pollen load for selected measuring sites on September 15, 2006. Numbers are given in percent

\begin{tabular}{lllll}
\hline Site & Sources in Hungary & Sources in Germany & Sources in Austria & $\begin{array}{l}\text { Sources in the } \\
\text { Czech Republic }\end{array}$ \\
\hline Berlin & 11.3 & 88.2 & 0.3 & 0.2 \\
Dresden & 56.3 & 0.0 & 0.0 & 43.7 \\
Garz & 50.0 & 0.0 & 0.0 & 50.0 \\
Potsdam & 16.6 & 82.0 & 0.7 & 0.7 \\
Treuenbrietzen & 17.5 & 80.1 & 0.7 & 1.7 \\
\hline
\end{tabular}


varying quality of the distribution maps. Presumably, the German sources are overestimated since the distribution map for Germany displays all administrative districts where ragweed stands with more than 100 plants can be found. The actual abundance as well as the number of big plant stands is not known. Because of that, an extensive coverage of $6 \%$ for the entire district is assumed. This value is merely fictitious: it lies in the lower range of the coverage in Hungary, but it might be still too high for Germany. Presumably, the influence of German sources is smaller than this study suggests. If this is true, the importance of the Hungarian sources rises.

\section{Importance of the individual source regions on local pollen counts}

To find out which source region should be considered in order to produce the best pollen forecast, simulations using all possible combinations of the available source regions were carried out. For each of the simulations, a $2 \times 2$ contingency table is generated by comparing the daily mean values of measured pollen concentrations and the daily mean values of the computed pollen concentrations at the closest grid point. Days $2-5$ of each simulation are used in the evaluation. The first day after initializing the model is left out in order to allow enough time for long-distance transport of the pollen to take place. By comparing the skill scores of the 15 simulations, the source regions that are essential for a good forecast can be found. A $2 \times 2$ contingency table can only consider whether a certain threshold value is reached or not. Quantitative information (e.g., concentration classes) cannot be included. Since we were mainly interested in the transport process, we chose a very low threshold value for the contingency table. A concentration as low as one pollen $\mathrm{m}^{-3}$ of air was counted as positive, in the simulations as well as in the measurements. The resulting values of the $2 \times 2$ contingency table and the computed skill scores for the 15 simulations can be found in Fig. 6 .

The skill scores Proportion Correct (PC) and Threat Score (TS) indicate the proportion of correct forecasts. For PC, all correct forecasts (hits and correct negations) are counted. TS only evaluates the hits, assuming that a correct negation is not as important as a hit. As can be seen in Fig. 6, TS scores are considerably lower than PC scores. This means that the non-events (pollen concentrations of less than one pollen $\mathrm{m}^{-3}$ ) are predicted better than the pollen events. But the prediction of non-events is of less importance to public health than the prediction of events. The health problems caused by allergies affect everyday life much more than the possible side effects of allergy medications. Therefore, TS is more meaningful for allergic people than PC. Overall, $30-43 \%$ of the events were predicted in the best simulations. The worst simulation is the one using only the Czech Republic as source region, the best simulation is the one considering all four source regions.

The skill scores Bias (B), Hit Rate (H), and False Alarm Rate (F) should always be looked at together. The Bias only depicts whether the correct number of events was forecast. But there is no information whatsoever whether these events coincide with the measured events. The Hit Rate gives the proportion of measured events that was correctly predicted. A simulation that always predicts an event results in a perfect value of 1 for $\mathrm{H}(100 \%$ of the measured events is predicted). But this does not make a good forecast since a lot of false alarms are issued. In practice, this means that forecasts will be ignored by the public. Because of that, the False Alarm Rate additionally needs to be considered. The shortcoming of $\mathrm{F}$ is the fact that a forecast that predicts no events at all would have a perfect score. An example for that case is simulation F (see Fig. 6) with pollen sources only in the Czech Republic. Not a single false alarm is issued and all three predicted events take place. But of course, the performance of the simulation is quite bad since the remaining 59 pollen events are not predicted, resulting in a very low score for the Hit Rate (less than $5 \%$ of the events were forecast). An overall comparison between the measurements in Germany and the simulations shows that the Bias is especially high when sources in Germany are considered. In some cases, more events are predicted than actually took place. This suggests that the German sources are overestimated in their present form. The simulations with a very low False Alarm Rate miss many of the measured pollen events. This is the case for the simulations $\mathrm{A}, \mathrm{C}, \mathrm{D}, \mathrm{J}$, and $\mathrm{K}$. All these simulations have in common that Germany is not considered as a pollen source. But Hungary as a source region should not be neglected. The best results were achieved when both Germany and Hungary were taken into account. This can be seen in the simulations E (all source regions), M (Germany, Hungary, Austria), and N (Germany, Hungary, Czech Republic). Their Hit Rates are much higher than the Hit Rate of simulation B (only German sources). At the same time, the probability of a false alarm is rising just slightly when Hungary is also considered. A good pollen forecast for Germany should therefore take into account the sources in Germany and Hungary.

The Heidke Skill Score (HSS) is a measure of how well a forecast performs in comparison to a forecast based on mere chance. Negative values mean that the simulation is worse than chance. Simulation C (sources only in Austria) is such a case (see Fig. 6). A value close to 0 denotes a forecast which performs comparably to chance. Positive values denote an improvement compared to a forecast by chance, with a value of 1 for a perfect forecast. In our case, the maximal value is 0.23 for the simulation with all available source regions. Again, the best results were 
Fig. 6 Values of the $2 \times 2$ contingency table and skill scores for the 15 simulations (compare Table 2 for the different combinations of source regions). The threshold value for the pollen concentration was 1 pollen $\mathrm{m}^{-3}$. The uppermost panel shows the number of entities $a, b, c$, and $d$ of the $2 \times 2$ contingency table. The 2nd panel shows the values of the skill scores Proportion Correct (PC) and Threat Score (TS). The 3rd panel shows the values of the skill scores Bias (B), Hit Rate (H), and False Alarm Rate (F). The lowest panel shows the values of the Heidke Skill Score (HSS)
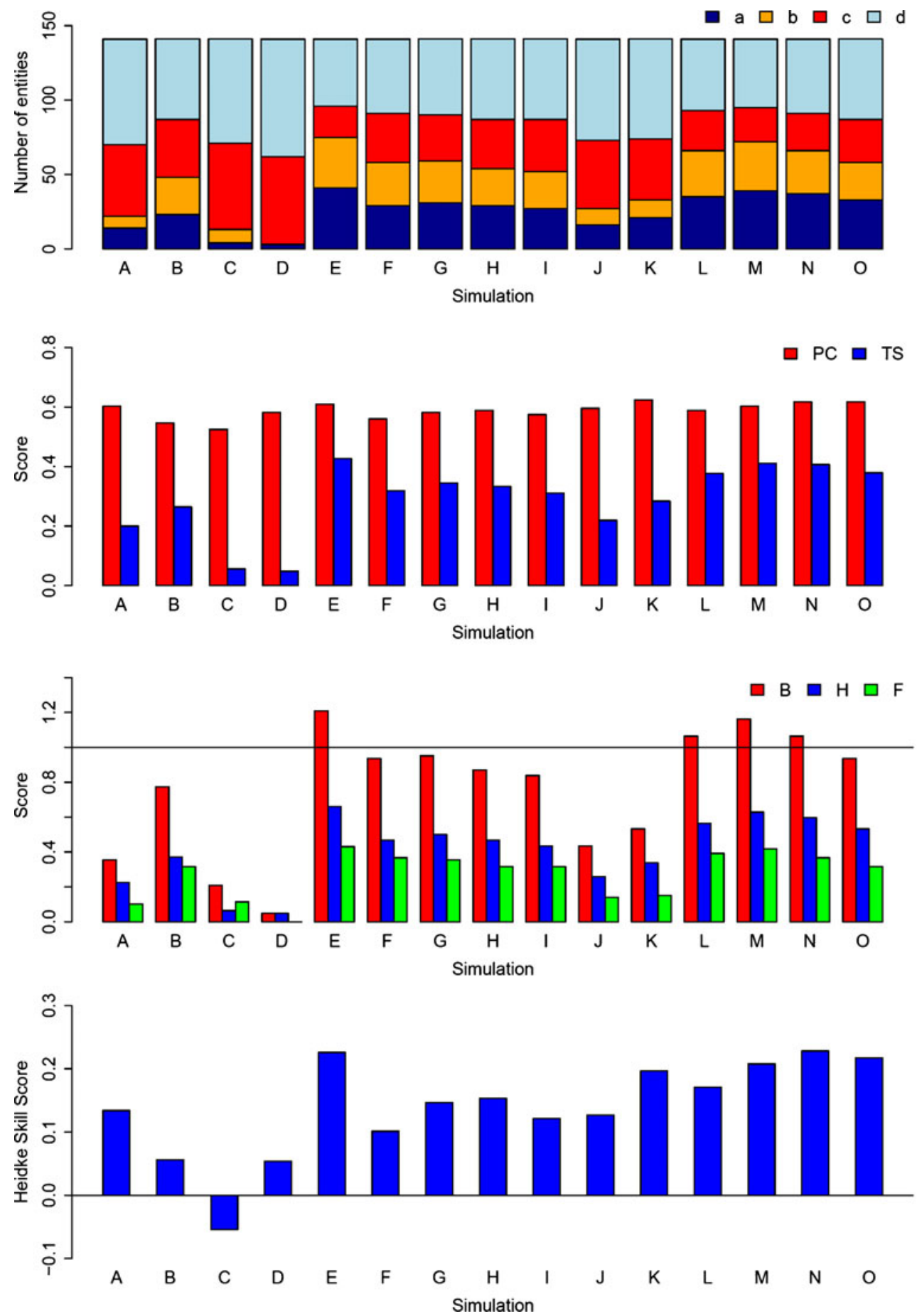

achieved when using both Germany and Hungary as source regions (simulations $\mathrm{E}, \mathrm{M}, \mathrm{N}, \mathrm{O}$ ).

\section{Conclusion}

It should be noticed that this was the very first attempt to simulate ragweed pollen in COSMO-ART. As such, the results are very promising.
Taking into account all of the computed skill scores, three simulations stand out from the others: simulation E (all source regions), M (Germany, Hungary, and Austria), and N (Germany, Hungary, and the Czech Republic). Obviously, both Germany and Hungary are essential for making a good prediction of ragweed pollen concentrations during the pollen episode we studied in north-eastern Germany. The majority of ragweed pollen measured in Germany originates from local sources as was shown with 
the four simulations that considered only one of the source regions. This can also be seen in the fact that the simulations with Germany as a source region better reproduce the number of pollen events than the simulations without Germany. Nevertheless, the predictions improve considerably when also taking into account the Hungarian pollen sources. The reason for that can certainly be found in the very dense plant distribution in Hungary that leads to the release of enormous amounts of pollen grains. Longdistance transport can bring this pollen to the north-eastern part of Germany. Furthermore, it was shown that the Czech and Austrian source regions are of minor importance during the pollen episode we studied. There are various reasons for that: pollen originating in Austria is not transported to north-eastern Germany under prevailing south-easterly winds; it can only influence the pollen concentrations in southern Germany. On the other hand, the Czech pollen sources in the model are small, and hence they are not able to release great amounts of pollen. Nevertheless, the geographical proximity to north-eastern Germany enhances their importance for the pollen concentrations in that region.

Acknowledgments We thank Mr. Kaminski and Ms. Kleinbauer for providing us with plant distribution data and pollen measurements. We thank Mr. M. Thielmann for the help with the data processing.

Open Access This article is distributed under the terms of the Creative Commons Attribution Noncommercial License which permits any noncommercial use, distribution, and reproduction in any medium, provided the original author(s) and source are credited.

\section{References}

Abul-Fatih HA, Bazzaz FA, Hunt R (1979) The biology of Ambrosia trifida L. III. Growth and biomass allocation. New Phytol 83:829-838. doi:10.1111/j.1469-8137.1979.tb02314.x

Albertenst B, Nawrath S (2006) Verbreitung in Deutschland. InfoPage Beifuß-Ambrosie. http:/www.ambrosiainfo.de/53223897640d5c602/ index.html. Accessed 15 March 2011

Bangert M, Kottmeier C, Vogel B, Vogel H (2011) Regional scale effects of the aerosol cloud interaction simulated with an online coupled comprehensive chemistry model. Atmos Chem Phys Discuss 11:1-37

Belmonte J, Vendrell M, Roure JM, Vidal J, Botey J, Cadahía A (2000) Levels of Ambrosia pollen in the atmospheric spectra of Catalan aerobiological stations. Aerobiologia 16:93-99. doi:10.1023/A:1007649427549

Bianchi DE, Schwemmin DJ, Wagner WH Jr (1959) Pollen release in the common ragweed (ambrosia artemisiifolia). Bot Gaz 120:235-243

Cecchi L, Morabito M, Domeneghetti MP, Crisci A, Onorari M, Orlandini S (2006) Long distance transport of ragweed pollen as a potential cause of allergy in central Italy. Ann Allergy Asthma Immunol 96:86-91. doi:10.1016/S1081-1206(10)61045-9

Cecchi L, Malaspina TT, Albertini R, Zanca M, Ridolo E, Usberti I, Morabito M, Aglio PD, Orlandini S (2007) The contribution of long-distance transport to the presence of Ambrosia pollen in central northern Italy. Aerobiologia 23:145-151. doi:10.1007/ s10453-007-9060-4
Clot B, Schneiter D, Tercier P, Gehrig R, Peeters A, Thibaudon M (2002) Ambrosia pollen in Switzerland-produced locally or transported? Allerg Immunol 34(4):126-128

Dahl A, Strandhede S-O, Wihl J-A (1999) Ragweed - an allergy risk in Sweden? Aerobiologia 15:293-297. doi:10.1023/ A:1007678107552

Dingle AN, Gill GC, Wagner Jr. WH, Hewson EW (1959) The Emission, Dispersion, and Deposition of Ragweed Pollen. In: Landsberg HE, Van Mieghem J (eds) Advances in Geophysics, vol 6. Elsevier, Netherlands, pp 367-387

Fumanal B, Chauvel B, Bretagnolle F (2007) Estimation of pollen and seed production of common ragweed in France. Ann Agric Environ Med 14:233-236

Gabrio T, Albertenst B, Behrendt H, Bucher K, Huss-Marp J, Kaminski U, Nawrath S, Weidner U (2008) Einfluss klimatischer Faktoren und ihrer bisherigen sowie erwarteten Änderung bezüglich der Zunahme von Sensibilisierungen am Beispiel von Ambrosia-Pollen. Statusseminar zum Forschungsvorhaben „Herausforderung Klimawandel Baden-Württemberg“. http:// www.herausforderung-klimawandel-bw.de/images/stories/ Vortrag Gabrio Ambrosia StatSem KA 080929.pdf. Accessed 16 March 2011

Helbig N, Vogel B, Vogel H, Fiedler F (2004) Numerical modelling of pollen dispersion on the regional scale. Aerobiologia 3:3-19. doi:10.1023/B:AERO.0000022984.51588.30

Jäger S (2000) Ragweed (Ambrosia) sensitisation rates correlate with the amount of inhaled airborne pollen. A 14-year study in Vienna, Austria. Aerobiologia 16:149-153. doi:10.1023/ A:1007603321556

Járai-Komlódi M (2000) Some details about ragweed airborne pollen in Hungary. Aerobiologia 16:291-294. doi:10.1023/A:1007660804839

Kasprzyk I (2008) Non-native Ambrosia pollen in the atmosphere of Rzeszów (SE Poland); evaluation of the effect of weather conditions on daily concentrations and starting dates of the pollen season. Int J Biometeorol 52:341-351. doi:10.1007/ s00484-007-0129-0

Köhler B, Gehrig R, Clot B, Ciotti V, Maspoli G (2006) Ambrosialuftpollenmessungen in der Schweiz: Quantifizierung des Gefahrenpotentials und Indikator für die Ausbreitung der Pflanze. Nachrichtenbl Deut Pflanzenschutzd 58:299-303

Laaidi K, Laaidi M (1999) Airborne pollen of Ambrosia in Burgundy (France) 1996-1997. Aerobiologia 15:65-69. doi:10.1023/ A:1007547919559

Laaidi M, Thibaudon M, Besancenot J-P (2003) Two statistical approaches to forecasting the start and duration of the pollen season of Ambrosia in the area of Lyon (France). Int $\mathrm{J}$ Biometeorol 48:65-73. doi:10.1007/s00484-003-0182-2

Lundgren K, Vogel B, Vogel H, Kottmeier C (2011) Direct radiative effects of sea salt on the regional scale for conditions of low to moderate wind speeds. J Geophys Res (submitted)

Makra L, Pálfi S (2007) Intra-regional and long-range ragweed pollen transport over southern Hungary. Acta Climatol Chorol 40-41:69-77

Makra L, Juhász M, Borsos E, Béczi R (2004) Meteorological variables connected with airborne ragweed pollen in Southern Hungary. Int J Biometeorol 49:37-47. doi:10.1007/s00484-004-0208-4

Makra L, Juhász M, Béczi R, Borsos E (2005) The history and impacts of airborne Ambrosia (Asteraceae) pollen in Hungary. Grana 44:57-64

Makra L, Sánta T, Matyasovszky I, Damialis A, Karatzas K, Bergmann KC, Vokou D (2010) Airborne pollen in three European cities: detection of atmospheric circulation pathways by applying three-dimensional clustering of backward trajectories. J Geophys Res 115:D24220. doi:10.1029/2010JD014743

Mandrioli P, Cecco MD, Andina G (1998) Ragweed pollen: the aeroallergen is spreading in Italy. Aerobiologia 14:13-20. doi:10.1007/BF02694590 
Mandrioli P, Caneva G, Sabbioni C (2003) Cultural heritage and aerobiology: methods and measurement techniques for biodeterioration monitoring. Kluwer, Dordrecht

Novák R, Dancza I, Szentey L, Karamán J (2009) Magyarország szántóföldjeinek gyomnövényzete. Ötödik Országos Szántóföldi gyomfelvételezés (2007-2008). [Weeds of the Hungarian arable lands. The fifth Hungarian weed survey on Arable Lands (2007-2008)]. FVM, Budapest, 94 pp. [in Hungarian]

Páldy A, Apatini D, Collinsné Horváth Z, Erdei E, Farkas I, Hardy T, Józsa E, Magyar D, Repulyik E, Barták G, Csontos F, Gallovich E, Oravecz A, Szeleczki T, Farkas L, Tarkóné Strifler A, Homonnai Z, Lengyelné Boldog I, Menner P, Nagy B, Péntekné Bóta E, Morozik L, Szabó H, Wimmer J, Laczik M, Borsányi A, Galambosiné Molnár E, Kis S, Somogyi Z, Bugir Z, Kulja A, Szintainé Dobrádi J, Tóth Z, Dulné Horváth T, Józsa K, Klatsmányi J, Németh I, Szalainé Vincze K, Nádor G (2006) Magyarország parlagfü-szennyezettsége 2000-2005. [Ragweed populations in Hungary. Egészségtudomány 50:39-60 [in Hungarian]

Pasken R, Pietrowicz JA (2005) Using dispersion and mesoscale meteorological models to forecast pollen concentrations. Atmos Environ 39:7689-7701. doi:10.1016/j.atmosenv.2005.04.043

Piotrowska K, Weryszko-Chmielewska E (2006) Ambrosia pollen in the air of Lublin, Poland. Aerobiologia 22:151-158. doi:10.1007/ s10453-006-9020-4

Puc M (2006) Ragweed and mugwort pollen in Szczecin, Poland. Aerobiologia 22:67-78. doi:10.1007/s10453-005-9010-y

Reinhardt F, Herle M, Bastiansen F, Streit B (2003) Ökonomische Folgen der Ausbreitung von Neobiota. Forschungsbericht 201686 211, Umweltbundesamt. Umweltforschungsplan des Bundesministeriums für Umwelt, Naturschutz und Reaktorsicherheit. UBA-FB 000441. pp 23-29

Riemer N, Vogel H, Vogel B, Fiedler F (2003) Modelling aerosols on the mesoscale-g: treatment of soot aerosol and its radiative effects. J Geophys Res 109:4601. doi:10.1029/2003JD003448

Rybníček O, Novotná B, Rybníčkova E, Rybníček K (2000) Ragweed in the Czech Republic. Aerobiologia 16:287-290. doi:10.1023/ A: 1007611715820

Saar M, Gudžinskas Z, Ploompuu T, Linno E, Minkienė Z, Motiekaityte V (2000) Ragweed plants and airborne pollen in the Baltic states. Aerobiologia 16:101-106. doi:10.1023/ A: 1007670229308

Schueler S, Schlünzen KH (2006) Modeling of oak pollen dispersal on the landscape level with a mesoscale atmospheric model. Environ Model Assess 11:179-194. doi:10.1007/s10666-006-9044-8
Skjøth CA, Smith M, Šikoparija B, Stach A, Myszkowska D, Kasprzyk I, Radišić P, Stjepanović B, Hrga I, Apatini D, Magyar D, Páldy A, Ianovici N (2010) A method for producing airborne pollen source inventories: an example of Ambrosia (ragweed) on the Pannonian Plain. Agric For Meteorol 150(9):1203-1210

Smith M, Skjøth CA, Myszkowska D, Uruska A, Puc M, Stach A, Balwierz Z, Chlopek K, Piotrowska K, Kasprzyk I, Brandt J (2008) Long-range transport of Amrosia pollen to Poland. Agric For Meteorol 148:1402-1411. doi:10.1016/j.agrformet.2008.04.005

Sofiev M, Siljamo P, Ranta H, Rantio-Lehtimäki A (2006) Towards numerical forecasting of long-range air transport of birch pollen: theoretical considerations and a feasibility study. Int $\mathrm{J}$ Biometeorol 50:392-402. doi:10.1007/s00484-006-0027-x

Stach A, Smith M, Skjøth CA, Brandt J (2007) Examining Ambrosia pollen episodes at Poznan (Poland) using back-trajectory analysis. Int J Biometeorol 51:275-286. doi:10.1007/s00484-006-0068-1

Stanelle T, Vogel B, Vogel H, Bäumer D, Kottmeier C (2010) Feedback between dust particles and atmospheric processes over West Africa during dust episodes in March 2006 and June 2007. Atmos Chem Phys 10:10771-10788. doi:10.5194/acp-10-10771-2010

Steppeler J, Doms G, Schättler U, Bitzer H, Gassmann A, Damrath U, Gregoric G (2002) Meso gamma scale forecasts using the nonhydrostatic model LM. Meteorol Atmos Phys 82:75-96

Stiftung Deutscher Polleninformationsdienst (2009) PID. http://www. pollenstiftung.de/. Accessed 20 April 2011

Taramarcaz P, Lambelet C, Clot B, Keimer C, Hauser C (2005) Ragweed (Ambrosia) progression and its health risks: will Switzerland resist this invasion? Swiss Med Wkly 135:538-548

Trigo MdM, García-Sánchez J (2006) Ambrosia artemisiifolia L., nueva especie para la flora alóctona invasora de Andalucía (España). Acta Bot Malacitana 31:203-205

Vogel H, Pauling A, Vogel B (2008) Numerical simulation of birch pollen dispersion with an operational weather forecast system. Int J Biometeorol 52:805-814. doi:10.1007/s00484-008-0174-3

Vogel B, Vogel H, Bäumer D, Bangert M, Lundgren K, Rinke R, Stanelle T (2009) The comprehensive model system COSMOART - radiative impact of aerosol on the state of the atmosphere on the regional scale. Atmos Chem Phys 9:86618680. doi:10.5194/acp-9-8661-2009

Wilks DS (2006) Forecast Verification. In: Wilks DS (ed) Statistical Methods in the Atmospheric Sciences, 2nd edn. Academic, Amsterdam, pp 260-276

Zanon P, Chiodini E, Berra D (2002) Allergy to ragweed in northern Italy and prevention strategies. Monaldi Arch Chest Dis 57(2):144-146 